\title{
Peningkatan Derajat Kesehatan Siswa SD 11 Kesiman Denpasar melalui Perilaku Hidup Bersih dan Sehat
}

\author{
I Gusti Ayu Putu Satya Laksmi ${ }^{*}$, Niken Ayu Merna Eka Sari ${ }^{2}$, Putu Ayu \\ Parwati $^{3}$, Ni Komang Ayu Resiyanthi ${ }^{4}$, Ni Luh Gede Intan Saraswati ${ }^{5}$ \\ $1,2,3,4,5$ STIKes Wira Medika Bali \\ *Email : ayuputusatya@yahoo.com
}

\begin{abstract}
Background: PHBS at school age that is not good enough will cause various diseases such as diarrhea, toothache, skin pain and worms. Thus, to reduce the prevalence of these bad impacts, it is important to apply PHBS. Methods: The method used is the lecture method. The team conducted health education related to Clean and Healthy Lifestyle, brushing teeth together, and examining faeces for worms. Results: there were 6 students' worms found, there were 10 students who had not brushed their teeth at night, all students listened well to the material that the team conveyed. Conclusion: Problem solving that can be done is by providing knowledge, understanding through counseling about PHBS.
\end{abstract}

Keywords: health degree, students, phbs

\section{PENDAHULUAN}

Sekolah merupakan tempat bagi siswa untuk belajar, terkadang bisa juga menjadi tempat dalam penularan penyakit jika tidak diperhatikan dengan baik terkait kebersihannya. Siswa sekolah dasar termasuk kelompok yang mudah terserang penyakit. Perilaku kesehatan anak sekolah dasar penting diterapkan dalam kehidupan sehari-hari, akan tetapi masalah/penyakit yang sering dihadapi oleh siswa SD yaitu kebersihan diri sendiri dan kebersihan lingkungan sekitar seperti cara menggosok gigi, perilaku mencuci tangan menggunakan sabun, cacingan, diare, anemia . Masalah-masalah yang sering dihadapi tersebut ternyata memiliki kaitan erat dengan Perilaku Hidup Bersih dan Sehat (PHBS) (Maryunani, 2013).

Menurut UU No.23 Tahun 1992 tentang kesehatan, pada pasal 45 menyatakan bahwa kesehatan sekolah diselanggarakan untuk meningkatkan kemampuan hidup sehat peserta didik dalam lingkungan hidup sehat sehingga peserta didik dapat belajar, bertumbuh dan berkembang secara harmonis serta optimal menjadi SDM yang bermutu. Kegiatan sekolah juga bertujuan untuk meningkatkan kebiasaan hidup sehat kepada siswa serta ikut aktif dalam peningkatan kesehatan terutama di sekolah.

Perilaku hidup bersih dan sehat ini merupakan salah satu program yang dibuat oleh pemerintah yang difokuskan pada kesehatan, bertujuan untuk meningkatkan derajat kesehatan masyarakat. Perilaku ini dapat diterapkan pada tatanan rumah tangga, sekolah, tempat kerja dan institusi kesehatan (Depkes RI, 2008). PHBS yang diterapkan di sekolah merupakan usaha yang dilakukan untuk memberdayakan siswa, guru, serta masyarakat lingkungan sekolah agar bisa menerapkan PHBS. Menurut Rahmawati (2012), anak usia sekolah menjadi salah satu sasaran PHBS yang berisiko menerapkan dan mengalami perilaku kesehatan kurang baik sehingga bisa menimbulkan penyakit diantaranya $\mathrm{BAB}$ lebih dari tiga kali, mengalami sakit pada gigi, serta bisa mengalami cacingan, yang dibuktikan dengan adanya cacing di 
feses anak. Sehingga untuk menekan dampak buruk yang bisa ditimbulkan maka penting menerapkan PHBS.

\section{TINJAUAN PUSTAKA}

\subsection{Perilaku Hidup Bersih dan Sehat (PHBS)}

PHBS yang dilakukan di sekolah merupakan usaha yang bisa dilakukan bersama-sama oleh siswa, guru, dan masyarakat yang tinggal di sekitar sekolah untuk melakukan perilaku sehat. Menurut Ahmadi (2003), sekolah merupakan bentuk lembaga yang berisikan struktur organisasi dengan segala macam kegiatan yang direncanakan dengan sengaja dan sering diistilahkan dengan kurikulum. PHBS di institusi pendidikan adalah upaya pemberdayaan dan peningkatan kemampuan untuk berperilaku hidup bersih dan sehat di tatanan institusi pendidikan. Menurut Depkes (2008), indikator PHBS di sekolah yaitu mencuci tangan menggunakan sabun dan air yang mengalir, kantin sekolah menyediakan jajanan sehat, menggunakan jamban yang bersih dan sehat, teratur berolahraga, memberantas jentik nyamuk, dilarang merokok, rutin menimbang BB dan mengukur TB, buang sampah pada tempatnya.

\subsection{Sasaran PHBS di Tatanan Sekolah}

Menurut Depkes RI (2008), sasaran PHBS di sekolah meliputi :

a. Sasaran primer

Meliputi individu/ kelompok dalam institusi pendidikan yang bermasalah (guru atau murid).

b. Sasaran sekunder

Pada poin ini,sasarannya adalah petugas kesehatan, tokoh masyarakat yang ada di sekitar sekolah, kepala sekolah.

c. Sasaran tersier

Seperti Dinas Pendidikan, kepala desa, lurah, camat, kepala puskesmas, serta orang tua murid.

Menurut Rahmawati (2012), mengurangi kejadian dari dampak buruk yang akan dimunculkan, penting diterapkan PHBS dengan memperhatikan :

a. Kebersihan gigi

Penting diperhatikan menggosok gigi dengan benar, dianjurkan setelah makan, menggunakan sikat gigi sendiri, jangan konsumsi makanan yang bisa merusak gigi, makan buah, mengecek keadaan gigi secara rutin ke dokter (Irianto, 2009).

b. Kebersihan Kaki, Kuku serta Tangan

Menurut Potter dan Perri (2005), terkait dengan kebersihan kuku, tangan, kaki yaitu selalu mencuci tangan sebelum makan, memotong kuku,dan menjaga kebersihan sekitar.

c. Olahraga

Terkait dengan kualitas gerakan dan kuantitas melakukan olahraga (Notoatmojo, 2007). 


\section{d. Tidur yang cukup}

Melakukan istirahat yang cukup merupakan kebutuhan dari manusia untuk mempertahankan kondisi kesehatannya (Notoatmojo, 2007). Dikatakan tidur sehat apabila udaranya bersih disekitar tempat tidur, suasana tenang dan cahaya lampu redup, serta kondisi tubuh yang nyaman saat tidur (Irianto, 2009).

\subsection{Kecacingan}

Makna kecacingan menurut Margono (2008) adalah penyakit infeksi yang diakibatkan oleh cacing. Cacing biasanya tidak menimbulkan penyakit berat sehingga sering diabaikan. Diantara jenis cacing ada beberapa yang proses penularannya melalui tanah atau biasa disebut dengan cacing jenis STH yaitu Ascaris lumbricoides, Necator americanus, Trichuris trichuira dan Ancylostoma duodenale (Margono et al., 2006). Kejadian ini sering ditemukan di wilayah beriklim tropis dan subtropis. Jenis penyakit ini adalah penyakit infeksi yang sering menyerang masyarakat yang memiliki ekonomi rendah (WHO, 2011), antara lain :

a. Dampak Infeksi Kecacingan

Keadaan ini dapat menyebabkan penurunan kondisi kesehatan sehingga secara ekonomi dapat menyebabkan banyak kerugian yang pada akhirnya dapat menurunkan kualitas sumber daya manusia. Kejadian infeksi cacing ini dapat dipengaruhi oleh perilaku, lingkungan disekitar tempat tinggal (Wintoko, 2014). Apabila mengalami infeksi dikarenakan oleh cacing gelang yang berat akan menyebabkan malnutrisi dan gangguan tumbang pada anak (Satari, 2010).

b. Pemeriksaan Soil Transmitted Helminth

Bentuk pemeriksaan feses bisa dilakukan dengan metode makroskopis dan mikroskopis. Pemeriksaan makroskopis untuk mengetahui warna, konsistensi, jumlah, bentuk, bau dan ada-tidaknya mucus, lemak, serat daging, empedu, sel darah putih dan gula. Pemeriksaan mikroskopis memiliki tujuan untuk mengetahui adanya parasit dan telur cacing.

\subsection{Kesehatan Gigi}

Kesehatan gigi dan mulut penting untuk anak usia sekolah. Usaha Kesehatan Gigi Sekolah (UKGS) melaksanakan kegiatan kesehatan gigi dan mulut secara teratur pada siswa di SD (Herijulianti, et al., 2002). Salah satu upaya yang bisa dilakukan untuk mengatasi masalah gigi dan mulut diantaranya upaya promotif. Bentuk upaya promotif yang dilaksanakan, lebih mengarah pada pendidikan kesehatan tentang gigi. Kegiatan ini dilakukan oleh guru, agar bisa tercapai dengan baik, bisa dengan cara memasukkan pelajaran tentang pentingnya menjaga kesehatan gigi dan mulut dalam kegiatan pembelajaran.

\section{METODE}

Adapun metode yang dipakai untuk menunjang pelaksanaan pengabdian masyarakat adalah : 
a. Pemeriksaan Cacing

Pemeriksaan dilakukan dengan teknik pemeriksaan feses langsung. Pemeriksaan ini dilakukan di hari saat siswa menyerahkan pot feses yang sudah berisi feses. Pemeriksaaan ini dilakukan oleh salah satu anggota tim dan mahasiswa di laboratorium Prodi D3 TLM STIKes Wira Medika. Satu hari sebelum kegiatan, masing-masing siswa diberikan pot feses oleh tim, untuk dibawa kembali dihari berikutnya. Berikut teknik dalam pemeriksaan sampel feses :

1) Reagensia dan Bahan : Feses dan Larutan $\mathrm{NaCl}$ fisiologis $0,9 \%$

2) Cara pemeriksaan sampel : meneteskan 1-2 tetes larutan $\mathrm{NaCl}$ fisiologis $0,9 \%$ pada kaca objek yang bersih. Tinja diambil seujung lidi $( \pm 2 \mathrm{mg}$ ) dengan menggunakan lidi, kemudian diaduk hingga rata pada larutan $\mathrm{NaCl}$ fisiologis $0,9 \%$ lalu ditutup dengan cover slip. Specimen diamati dibawah mikroskop mula-mula pembesaran 10x objektif dan kemudian dilanjutkan dengan lensa objektif 40x objektif.

3) Interprestasi hasil

Positif : Jika ditemukan telur dan atau larva atau cacing dewasa dalam specimen tinja. Negatif : Jika tidak ditemukan telur dan atau larva atau cacing dewasa dalam specimen tinja.

b. Kegiatan Gosok Gigi Bersama

Kegiatan ini diawali dengan koordinasi dengan pihak sekolah,terutama guru untuk mengkoordinasikan kegiatan gosok gigi bersama oleh siswa. Setelah diberi ijin, tim meminta bantuan ke wali kelas untuk menyampaikan ke siswa terkait kegiatan ini. Tim menyiapkan semua perlengkapannya, mulai dari sikat gigi dan pasta gigi. Pada hari yang sudah ditentukan, tim mengawali dengan memberikan penyuluhan kesehatan gigi, mengidentifikasi siswa yang sudah melakukan gosok gigi di malam hari. Setelah itu, dilanjutkan dengan mengajak siswa untuk melakukan sikat gigi bersama dihalaman sekolah, didampingi oleh tim serta beberapa guru. Setelah semua kegiatan ini selesai, tim meminta bantuan kepada wali kelas untuk mengevaluasi di hari-hari berikutnya terkait menjaga kebersihan gigi dan kebiasaan gosok gigi dimalam hari.

c. Kegiatan Penyuluhan PHBS. Kegiatan ini dilakukan di kelas, di hari bersamaan dengan penyuluhan kebersihan gigi. Materi yang disampaikan terkait PHBS secara umum. Cara yang digunakan oleh tim dalam kegiatan ini adalah metode ceramah menggunakan bantuan LCD proyektor.

\section{HASIL}

Tabel 1. Karakteristik Siswa

\begin{tabular}{lcc}
\hline Jenis kelamin & Frekuensi (F) & Persentase (\%) \\
\hline Laki-laki & 13 & 32.5 \\
\hline Perempuan & 27 & 67.5 \\
\hline
\end{tabular}

Berdasarkan tabel 1 didapatkan hasil bahwa sebagian besar jenis kelamin siswa adalah perempuan sebanyak 27 (67.5\%). 
Tabel 2. Gambaran Terdeteksi Kecacingan

\begin{tabular}{lcc}
\hline Terdeteksi Cacing & Frekuensi (F) & Persentase (\%) \\
\hline Terdeteksi & 6 & 15 \\
\hline Tidak terdeteksi & 34 & 85 \\
\hline
\end{tabular}

Berdasarkan tabel 2 didapatkan hasil bahwa sebagian besar siswa tidak terdeteksi oleh cacing yaitu sebanyak 34 (85\%).

Tabel 3. Gambaran Gosok Gigi dimalam Hari

\begin{tabular}{|c|c|c|}
\hline Gosok Gigi dimalam Hari & Frekuensi (F) & Persentase $(\%)$ \\
\hline Dilakukan & 30 & 75 \\
\hline Tidak dilakukan & 10 & 25 \\
\hline
\end{tabular}

\section{PEMBAHASAN}

Hasil penelitian menunjukkan bahwa sebagian besar siswa tidak terdeteksi cacing, akan tetapi ada ditemukan sebanyak 6 siswa terdeteksi cacing. Berdasarkan wawancara dengan siswa,didapatkan hasil bahwa siswa yang terdeteksi cacing mengatakan bahwa sering lupa untuk cuci tangan sebelum makan dan kuku tangannya kotor. Seperti yang tertuang dalam poin dari PHBS di sekolah menurut Depkes, 2008 meliputi cuci tangan di air mengalir dan menggunakan sabun, makan jajanan yang sehat. Selain itu, berdasarkan hasil observasi tim, terbukti beberapa fasilitas yang masih kurang mendukung dari pihak sekolah, salah satunya yaitu terbatasnya tempat mencuci tangan. Penting diperhatikan terkait dampak infeksi kecacingan, keadaan ini dapat menyebabkan penurunan kondisi kesehatan sehingga secara ekonomi dapat menyebabkan banyak kerugian yang pada akhirnya dapat menurunkan kualitas sumber daya manusia (Wintoko, 2014).

Selain kejadian kecacingan, ditemukan ada 10 siswa yang tidak gosok gigi dimalam hari. Berdasarkan wawancara dengan siswa, penyebab dominan siswa tidak menggosok gigi dikarenakan sudah mengantuk dan tidak terbiasa gosok gigi di malam hari. Seperti yang dijelaskan oleh Herijulianti, et al., (2002), salah satu upaya yang bisa dilakukan untuk mengatasi masalah gigi dan mulut diantaranya adalah upaya promotif, lebih mengarah pada pendidikan kesehatan tentang gigi. Kegiatan ini bisa dilakukan terutama oleh guru, agar bisa tercapai dengan baik, bisa juga dengan cara memasukkan pelajaran tentang pentingnya menjaga kesehatan gigi dan mulut dalam kegiatan pembelajaran. Selain itu penting setiap sekolah menyediakan pelayanan kesehatan gigi dan mulut pada anak usia sekolah yaitu untuk memperoleh generasi yang sehat, seperti Usaha Kesehatan Gigi Sekolah (UKGS) yang tersedia di sekolah (Herijulianti, et al., 2002). Penelitian lain yang mendukung yaitu menurut Effendi (2003), penyuluhan kesehatan merupakan salah satu cara untuk menyampaikan informasi secara efektif guna meningkatkan pengetahuan sekelompok orang yang menjadi sasaran program. 
Apabila informasi yang disampaikan benar-benar dapat diterima dengan baik, maka peserta dapat mengaplikasikan informasi tersebut dalam pratek sehari-hari terutama dalam pengendalian infeksi kecacingan pada anak-anak.

\section{KESIMPULAN DAN SARAN}

Penerapan perilaku hidup bersih serta sehat oleh siswa sangat berkaitan dengan kejadian kecacingan serta kurangnya kesdaran menggosok gigi di malam hari pada siswa kelas IV SD 11 Kesiman Denpasar. Sehingga,penting meningkatkan perilaku bersih dan sehat baik di sekolah ataupun dari kesadaran dari siswanya.

\section{UCAPAN TERIMA KASIH}

Disampaikan kepada Kepala Sekolah, para guru SD 11 Kesiman Denpasar, siswa yang telah terlibat dan berperan aktif dalam kegiatan, PPPM STIKes Wira Medika yang telah mendanai kegiatan ini sehingga bisa berjalan dengan baik. Mahasiswa dan mahasiswi dan teman dosen yang sudah banyak membantu pengabdian kepada masyarakat ini sehingga bisa terlaksana dengan baik.

\section{DAFTAR RUJUKAN}

Ahmadi, A. (2003). Psikologi Belajar Edisi Revisi. Jakarta: Rineka Cipta.

Depkes RI. (2008). Buku Saku Pelaksanaan PHBS Bagi Masyarakat Di Wilayah Kecamatan. Jakarta : Kemenkes.

Effendy, Uchjana O. (2003). Ilmu, Teori, dan Filsafat Komunikasi. Bandung: PT. Citra Aditya Bakti

Herijulianti, E. dkk. (2002). Pendidikan Kesehatan Gigi. Jakarta:EGC.

Margono S, Tatang, RS, Sansongko A, Irawan HSJY, S. R. (2006). Result of a Control Program on Soil Transmitted Helminthiases in Primary Schools of East Jakarta Indonesia. Kuala Lumpur : Second International Congress of Parasitology and Tropical Medicine.

Margono S. (2008). Buku Ajar Parasitologi Kedokteran (Edisi 4). Jakarta : FK UI.

Maryunani, A.(2013). Perilaku Hidup Bersih dan Sehat (PHBS). Jakarta : Trans Info Media

Musadad, A., \& Irianto, J. (2009). Pengaruh Penyediaan Air Minum Terhadap Kejadian Karies Gigi Usia 12-65 Tahun Di Provinsi Kepulauan Bangka Belitung Dan Nusa Tenggara Barat (Analisis Lanjut Riskesdas 2007). Indonesian Journal of Health Ecology, 8(3), 78822. 
Notoatmodjo. (2007). Promosi Kesehatan dan Ilmu Perilaku. Jakarta: Rineka Cipta.

Potter, P.A., \& Perry, A. G. (2005). Buku Ajar Fundamental Keperawatan: Konsep, Proses, dan Praktik. (Edisi 4.Vo). .Jakarta:EGC.

Rahmawati, E. (2012). Perilaku Hidup Bersih dan Sehat. Yogyakarta: Nuha Medika.

Satari, H. (2010). Buku Ajar Infeksi dan Pediatri Tropis. Edisi Kedua. Jakarta: IDAI, hlm. 370-84.

Wintoko, R. (2014). Hubungan aspek Personal Hygiene dan Aspek Perilaku Dengan Kontamniasi Telur Cacing pada Kuku Siswa Kelas 3, 4 dan 5 di SDN 2 Rajabasa Kabupaten Bandar Lampung Tahun Ajaran 2012/2013. Juke Unila, 4(7): 136-41.

World Health Organization (WHO). (2011). Intestinal worms, soil transmitted helminths. 